\title{
AUSENCIA Y PRESENCIA DE LAS VANGUARDIAS EN COLOMBIA
}

\author{
POR \\ ARMANDO ROMERO \\ University of Pittsburgh
}

\section{INTRODUCCIÓN}

No es posible realizar un análisis del acontecer literario colombiano actual sin antes emprender una valoración o revaloración de los movimientos de vanguardia en el país en la primera mitad de este siglo, señalando en ellos lo que se ha venido a denominar como vanguardia, o sea, los postulados que vieron amanecer a comienzos del siglo impulsados por el vuelo sugerente del simbolismo, las superficies pulidas del parnaso, la luz difusa del impresionismo y el hálito siempre vivo del romanticismo, para llegar al cubismo, dadaísmo, surrealismo, creacionismo, ultraísmo, etc. Pero esto presupone una búsqueda casi a nivel individual $\mathrm{y}$ un recuento de islas e islotes que manchan esa cara de país católico y conservador por excelencia. No podría entenderse de otra manera la floración, si la hubo, de las vanguardias en Colombia si antes no revisamos (como mea culpa y catarsis), aunque sea rápidamente, el panorama político y social en que se inscriben.

La historia de Colombia, que señala su independencia dinámica a manos de Bolívar a principios del siglo XIX, no será de allí en adelante más que la sucesión de políticos siguiendo las líneas económicas de turno, en labor de vigilancia de sus propios intereses y el de sus patrones. Con ligeros rasgos de liberalismo en algunos momentos, no hay nada de mención en este viaje al fondo de la noche, y los nombres será mejor no recordarlos. Las guerras civiles vienen a matizar el cuadro con sus muertos sin justicia ni razón.

Parecerá crudo, ligero, despiadado o parcializado este análisis expresionista de la situación colombiana, pero no hay otra verdad a mano que sirva para revelar lo que realmente es este país, que por años se ha 
ufanado de estar poblado de humanistas, poetas e intelectuales del más alto coturno y prosapia; lo único cierto es que, amparándose en el nombre de unos cuantos científicos, gramáticos y poetas del siglo pasado, la burguesía nacional — semifeudal y reaccionaria hasta decir Jesús- ha vendido internacionalmente un cuadro publicitario que le sirve sólo para ampararse frente a una realidad de analfabetos miserables, de niños tirados en la calle, de prostitutas a dos por cinco y viciosos de toda calaña y efecto. $Y$ nada ha cambiado, con más extraña y comprensible razón para los entendidos si pensamos que entre los presidentes de este siglo figuran hombres que fueron activos integrantes de los movimientos culturales de principios de siglo (véase el caso de Laureano Gómez, que perteneció al grupo de «El Centenario», y el de Alberto Lleras, fundador del grupo de «Los Nuevos»). Hoy como ayer, al escritor colombiano sólo le queda tiempo para el exilio, un puesto en la empresa privada y la renuncia a toda posibilidad de influir en su país.

Ahora bien: es necesario volver a repetir aquí que la hipocresía de la clase dominante colombiana siempre presentó una imagen de maravillas, ayudada por una intelectualidad que de una u otra manera le era fiel; pero la realidad es distinta. De las excepciones oscuras en cuanto a influencias y presencias y de los exilios internos o externos sacaremos entonces la vanguardia colombiana y sus postulados de lucha y cambio.

\section{ANTECEDENTES}

En un ensayo publicado recientemente, Fernando Charry Lara anotaba que toda revisión de la poesía colombiana en lo que va de este siglo no podría prescindir de José Asunción Silva, aunque este poeta vivió y murió en el siglo pasado:

Habría un motivo, en realidad bastante simple, para justificarla. Los versos de Silva, que en vida del poeta permanecieron más o menos ocultos, vinieron a ser difundidos apenas en los primeros años del novecientos. Pero es indudable también la existencia de un argumento más poderoso. $\mathrm{Y}$ es el de que los poemas significativos de Silva, como los de ningún otro poeta colombiano del pasado siglo, están más cerca de la sensibilidad poética contemporánea ${ }^{1}$.

Es así claro que con Silva los colombianos despiertan a una realidad más amplia y abren puertas entonces cerradas por la mediocridad reinan-

\footnotetext{
${ }^{1}$ Fernando Charry Lara, «Poesía colombiana del siglo xx», Eco, agosto 1979, núm. 214, p. 337.
} 
te, que con las excepciones probables de José E. Caro y Rafael Pombo se mantendrán hasta la generación de «El Centenario», donde se reunieron varios de los más pulcros cavernícolas que país alguno haya ofrecido jamás, extrayendo de este apelativo a José Eustacio Rivera y a Eduardo Castillo. Silva, a pesar de su corta vida, entró en contacto con los más importantes espíritus simbolistas que ya aleteaban por debajo de las futuras vanguardias. Su predilección por Baudelaire, Verlaine, Mallarmé y su reconocimiento profundo de la obra de Poe, maestro de todos ellos, lo sitúan en la encrucijada precisa, a nivel de lucha con el lenguaje y disparo de la sensibilidad, que produciría todos los movimientos artísticos del siglo xx. Silva era demasiado para esa pacata Colombia de políticos ambiciosos y señoras encorsetadas, y por eso se suicidó, dejando la alternativa a futuros trabajadores de la belleza y el arte, que no vinieron fácilmente, que necesitaron la vuelta del siglo y casi la vuelta del otro siglo para emerger.

El preciosismo formal de Guillermo Valencia, su rigidez mental de camello enredado en las puertas de un templo griego y su actividad parlamentaria de corroboración y apoyo a las fuerzas más oscuras de la política colombiana, lo colocan en los antípodas de lo que podría representar un precursor de la vanguardia colombiana. Pero si José A. Silva representa un padre espiritual del nuevo quehacer literario, y por eso lo consideramos importante, Valencia cobra valor en ser lo opuesto, en permitir que su obra se convierta en blanco de tiro para los movimientos que vendrán después, incluido el nadaísmo y excluido «El Centenario», sobre el cual influyó decisivamente.

Este grupo de «El Centenario» debe su nombre a que sus integrantes comenzaron a publicar hacia 1910, fecha del centenario de la independencia. No tenemos noticia de que formaran un grupo abanderado bajo una consigna o búsqueda particular, sino más bien que representaban la inteligencia colombiana del momento. Influidos por el peor modernismo, agruparon a un poderoso tanque intelectual y político, entre quienes destacan los liberales Alfonso López y Eduardo Santos y el conservador Laureano Gómez, todos ellos posteriormente gloriosos presidentes de la inmortal República. Salvo Eduardo Castillo, poeta de rara sensibilidad, mezcla de simbolista y romántico, y hombre de gran cultura, quien dejó una obra de delicado sabor y luz tenue, para decirlo a la manera de la crítica colombiana, y José E. Rivera, quien se derramó poéticamente en La vorágine, pero que como poeta fue formal y descriptivo, sin verdadera garra vital; poetas estos dos que aunque conocían la obra de Baudelaire, Verlaine, Rimbaud o Mallarmé y, presumiblemente, la de algunos poetas europeos y americanos contemporáneos a ellos, no lograron reconocer la 
profundidad inherente a una nueva expresión poética, y así, en momentos en que Huidobro ya enterraba en las flores sus lanzas creacionistas, estos amables bardos colombianos cantaban a «la lejana novia de blanca túnica ceñida» (Eduardo Castillo, soneto «Ella») o a la «brisa de inefable ruido» (José E. Rivera, soneto "Hay una brisa...») ${ }^{2}$; pero de todas maneras, ellos estaban entre los primeros en respirar o en hacer respirar unas pocas partículas de polución vanguardista, ya fuera en el ensayo de Castillo o en la prosa de Rivera.

Ahora bien: si es cierto que poca escritura de creación propiamente dicha revela la presencia de la vanguardia durante estos años de comienzos de siglo, no sucede así con el ensayo crítico, que sí nos da una imagen en movimiento del pensamiento colombiano en esta época. Tal vez esto se deba a esa particularidad colombiana de criticar y señalar a otros lo que hay que hacer en vez de hacerlo nosotros mismos, pero de todas maneras el hecho es que desde finales del siglo pasado una voz como la de Baldomero Sanín Cano ya había estado indicando la necesidad de cambio o liberación de los moldes conservadores. Su valiente posición política, que lo llevó a retratar fielmente a Colombia, a la que describió acremente como una república fósil, y su acerada pasión por renovar el fondo de la cultura nacional, lo hacen quizá el más lúcido e interesante crítico colombiano de este siglo. Sanín Cano se enfrentó contra los regionalismos, contra los falsos nacionalismos y contra aquellos que detentando el poder continuaban un estado lamentable de cosas.

\section{LAS DOS PRIMERAS ISLAS}

Metidos por estos años de transición y cambio dentro de lo mismo, encontramos a Porfirio Barba Jacob y a Luis Carlos López, poetas distantes geográfica y mentalmente, pero que empiezan a enviar sus luces fuera de los grupos habituales capitalinos, que tradicionalmente habían acaparado la mayor parte de la producción (entiéndase difusión) literaria en el país.

Barba Jacob, romántico de piel umbrosa y modernista extravagante, va a alimentar con su poesía andariega el alma en penumbra de los colombianos. Odiado y amado con igual vehemencia, su poesía, que no presenta, a nuestro juicio, un verdadero fondo vanguardista, continúa

${ }^{2}$ Eduardo Castillo, «Ella», y José E. Rivera, «Hay una brisa...», en Andrés Holguín, Antología crítica de la poesía colombiana (1874-1974) (Bogotá: Biblioteca del Banco de Colombia, 1974), pp. 178 y 186. 
acelerando debates y divergencias. Pero tal vez el problema sea exterior a su lirismo y sí relacionado con esa práctica vital de precursor tropical de los beatnicks, que lo distancia del poeta típico colombiano, el cual se apoltrona para alcanzar el secreto de la existencia. $Y$ en esto estaría su aporte vanguardista, más en su actitud poética que en la realización del poema mismo.

Pero mientras Barba Jacob arde en el fuego de su satanismo centroamericano, en la cálida Cartagena de Indias Luis Carlos López disecará fríamente la estupidez provinciana nacional. Desde su primer libro, publicado en 1906, este costumbrista rabioso va a comenzar una fiesta de juegos y travesuras dentro del poema, y todo como pretexto para aplastar la cursilería reinante, producto del trasnochado modernismo de cisnes almibarados. «Los modernistas estaban dominados por el sueño de la unidad del símbolo: para ellos, el mundo se unía con una totalidad verbal. Con Luis C. López - amargo y lúcido- en Colombia, Manuel Bandeira en el Brasil y César Vallejo en el Perú, la historia pulverizada, multiplicidad de lo humano en trance de expresión, hace su entrada al poema», escribe Jorge Gaitán Durán ${ }^{3}$.

El humorismo de López, su desenfado al meter en el poema al vecino o a las púdicas muchachas de provincia, a sus zapatos viejos o a sus novias de ocasión, lo aproximan a algunos postulados de la vanguardia (recordemos a la distancia, y con el debido respeto, el poema vibrante y directo de Blaise Cendrars o la ironía veloz de Prévert), pero su reticencia a salir de los moldes de la rima, del soneto o de las formas más bien clásicas de la poesía, contrariando en esto los buenos consejos de su maestro Unamuno, hace que su obra sólo llegue hasta la efervescencia de sus fronteras de isla y no se entronque más adentro del continente de la poesía nacional. Influiría, sí, al torcerle la cerviz a unos no tan elásticos camellos.

\section{«Los Nuevos»}

Ya en 1918, Eduardo Castillo, en una conferencia sobre los jóvenes poetas colombianos dictada en Bogotá, señalaba entre otros a León de Greiff y a Rafael Maya, quienes vendrían a constituirse, al correr de los años, en entidades opuestas en la poesía colombiana. Las ideas para el cambio, propicias a los aires de vanguardia, estaban comenzando a rebo-

${ }^{3}$ Jorge Gaitán Durán, Obra literaria (Bogotá: Instituto Colombiano de Cultura, 1975), p. 446. 
tar por las montañas del país: en 1915 León de Greiff publica en Medellín la revista Pánida, y el viento nórdico, extranjero y vernáculo, de una poesía irreverente, irónica, suelta y golpeante, se siente en toda Colombia. Al hablar del poeta, Castillo decía en ese entonces que «se trata, pues, de un artista contradictorio, paradójico y a veces extravagante y absurdo que escapa a todo ensayo de captación crítica, a toda tentativa para abarcar los diversos aspectos y modalidades de su talento» ${ }^{4}$, y hasta hoy día los críticos no irán más lejos con sus asertos.

En su libro Tergiversaciones, publicado en 1925, De Greiff atiende al llamado de González Martínez de mirar «al sapiente búho»:
Místicos, tétricos, los hondos
búhos señeros, funeral
treno balbucen, y redondos
flechan sus ojos luz mental 5 .

Pero ya De Greiff no le estaba torciendo el cuello al cisne ni al camello; se los estaba comiendo vivos con sus canciones y relatos trovadorescos, de juglar muy antiguo y muy moderno. El modernismo alimentaba su mundo de imágenes rutilantes y saltarinas, pero no condicionaba su música, propia, particular y abscóndita, ni su ritmo burlón y barroco. En él todas las presencias son alas: Laforgue, Banville, Verlaine, Poe, Mallarmé, Lautréamont, Rimbaud y el empuje de las vanguardias en acción. Palabras en desuso, olvidadas y antiguas o neologismos estallantes de actualidad, formas estructurales barrocas, culteranistas, filiaciones oscuras con la Edad Media y las culturas nórdicas primitivas, pasión por personajes comunes que saltan líricamente dentro de sus poemas, retruécanos, metáforas insólitas, humor zumbón de sacabuche irónico, adjetivaciones bruscas, sonoras y un mundo alucinante: Bolombolo, El Cauca, Antioquía, Colombia, Escandinavia... León de Greiff va a ser inscrito oficialmente en la literatura colombiana como integrante del grupo de «Los Nuevos».

Pero antes de detallar este grupo, receptor y amplificador en cierta forma de las ideas de vanguardia, valga la pena entrar, de la mano de Luis Tejada, hombre de corta y lúcida vida, quien influyó decisivamente en el pensamiento literario del país en esa turbulenta década del 20:

${ }^{4}$ Eduardo Castillo, Tinta perdida (Bogotá: Ediciones del Ministerio de Educación, 1965), pp. 121-122.

${ }^{5}$ León de Greiff, Tergiversaciones de Leo Gris, Aldecoa y Gaspar. Primer mamotreto (Bogotá: Tip. Augusta, 1925). 
Este país es esencialmente conservador en todos los aspectos de su vida - escribía en 1922-, pero singularmente en lo que se refiere a la literatura. Nadie experimenta aquí la inquietud del porvenir, ni siquiera del presente. Todos son inmunes a los gérmenes de renovación, y preferimos encerrarnos en la contemplación del pasado antes de adoptar una actitud de simpatía activa, incorporándonos a la agitada vida que transcurre fuera, uniéndonos por algún hilo vital al mundo conmovido y maravilloso que va en marcha hacia adelante ${ }^{6}$.

Sin embargo, el hecho de que él lo pensara así era intuición y piedra para el cambio, el cual, si bien no se produjo en la escala necesaria, por lo menos permitió que durante este período nuevas ideas y acciones se ventilaran en el país. El grupo de «Los Nuevos» debe su nombre a la revista homónima que fundaron los hermanos Felipe y Alberto Lleras Camargo. Alrededor de esta publicación estuvieron Jorge Zalamea, Jorge Eliécer Gaitán, Gabriel Turbay, Otto y León de Greiff, Germán Arciniegas, Ricardo Rendón, Luis Tejada, Rafael Maya, Silvio Villegas, Luis Vidales, José Mar, Octavio Amortegui, Germán Pardo García, Augusto Ramírez Moreno, Carlos y Juan Lozano, José Umaña Bernal.

Alberto Lleras escribía en 1926:

Hemos sostenido desde hace mucho tiempo la tesis de que «Los Nuevos» tienen una psicología diametralmente opuesta, no sólo contraria, sino contradictoria, a la de las generaciones que los precedieron. Una sensibilidad más exquisita a los motivos universales y una más fácil adaptación a la idea, todo lo cual les da una apreciación distinta, más global, más de conjunto sobre las cosas y los hombres?

Y más adelante:

Ese es el defecto de nuestra literatura. No vemos por ninguna parte el poeta. Vemos apenas el improvisador de banquete, el que celebra siempre con una elegía enternecida un duelo social, el que canta los esplendores de una fiesta, o el que, desde un salón alfombrado, siguiendo la misma parábola sentimental que se sigue en el Trianón, en el Imperio, busca sus motivos en un campo ficticio, en labriegos imaginarios y pulidos, en eruditas campesinas que todas tienen invariablemente «las mejillas rosadas». La vida verdadera, que no depende

${ }^{6}$ Luis Tejada, artículo en el diario El Espectador, 1922. Reproducido en Luis Vidales, Suenan timbres (Bogotá: Instituto Colombiano de Cultura, 1976), p. 13.

${ }^{7}$ Alberto Lleras, en un artículo publicado a raíz de la primera edición de Suenan timbres, 1926. Reproducido en Luis Vidales, Suenan timbres, op. cit., p. 203. 
de la concepción que de ella pueda tener la novia del poeta, desaparece casi totalmente de nuestra poesía ${ }^{8}$.

Lleras defendía el humor como insurrección y nuevo estilo, amparado por el éxito en cuanto a rechazo, agravio, desconcierto y burla que el libro Suenan timbres, de Luis Vidales, había causado entre la sociedad bogotana. ¡Qué lejos y qué cerca estaba Lleras del arrogante y despótico presidente colombiano de finales de la década del 50 !

Pero quedémonos con Luis Vidales. Es cierto que Colombia es conservadora, clerical y atrasada, siempre lo ha sido, por lo demás; sin embargo, en esta década del 20 las ideas de renovación hacen su aparición turbulentamente en el país. La influencia política de la Revolución rusa y de Lenin se hace sentir y algunos de "Los Nuevos» siguen fielmente estos postulados: Tejada, Vidales, Mar, Zalamea, De Greiff, entre otros. Se discuten las proposiciones surrealistas, dadaístas, futuristas. Sanín Cano, en uno de sus escritos, señala las contradicciones de Marinetti y defiende el despertar de una nueva conciencia y el cambio. E1 liberalismo, que había estado fuera del poder por más de cuarenta años, empieza a coger fuerza nacional. El general Benjamín Herrera, caudillo liberal, logra un acuerdo entre las ideas del socialismo naciente y las liberales, a la vez que patrocina grupos y movimientos que empujan hacia nuevos derroteros. Pero esta apertura hacia el socialismo se vería frustrada por el pacto con el conservadurismo auspiciado por eỉ liberal Olaya Herrera, precursor inmarcesible del Frente Nacional. Durante estos años la burguesía emergente ha creado la línea de ferrocarriles, que moverá económicamente al país; estallan los conflictos laborales: 1924, huelga en Barrancabermeja contra la Tropical Oil, subsidiaria norteamericana: son despedidos 1.200 obreros; 1926 , se reúne el Tercer Congreso Obrero en Bogotá con multitudinaria asistencia; 1927, surge el Partido Socialista Revolucionario y son sus líderes Tomás Uribe Márquez, Ignacio Torres Giraldo y María Cano, llamada «La flor del trabajo»; 1928, masacre en las bananeras; 1930, el liberalismo toma el poder.

Suenan timbres es quizá la obra más importante, a nivel de choque social y cultural con la sociedad, que se produce en Colombia hasta el advenimiento apocalíptico del nadaísmo, a finales de la década del 50. El mismo Vidales lo recuerda así al prologar la segunda edición de su obra en 1976:

Suenan timbres es un libro de demolición. Había que destruirlo todo: lo respetable, establecido o comúnmente aceptado, la moral y las

${ }^{8}$ Ibid., p. 205. 
buenas costumbres, sin descartar la poesía manida. La rima debía saltar en pedazos. La solemnidad social fue el blanco obligado del humorismo mezclado de ternura de un espíritu de la Colombia profunda, para el cual eran transparentes la falsedad y la majadería del comportamiento social, que aún hoy la retrae y causa leve sonrisa ${ }^{9}$.

\section{Y Eduardo Carranza lo corrobora:}

Es necesario decir que Luis Vidales fue, entre sus contemporáneos, el único que se plantó con un libro extraordinario en la vanguardia, el único que incorporó a su poesía las nuevas criaturas lucientes de la técnica, la inquietud revolucionaria que insurgía con las primeras victorias del socialismo, y los tesoros oníricos que venían de la inmersión freudiana en el subconsciente. Y no se trataba tan sólo de piruetas metafóricas ni del baile de la cuerda floja de la retórica descoyuntada. La obra primigenia de Vidales, aunque menor en influjo y extensión, equivale dentro de los límites colombianos a la del gran Vicente Huidobro en Chile ${ }^{10}$.

Vidales niega, sin embargo, toda asociación con grupo conocido, dadaísta, surrealista, ultraísta o seguidor de las greguerías de Ramón Gómez de la Serna; pero es obvio que en él hay de todo eso, y de menos, ya que su poesía posterior desdice mucho de su avanzada vanguardista, refugiándose ella en la consignería política y el soneto de encargo social.

En balance, el grupo de «Los Nuevos» sólo presenta hombres que, como Tejada, De Greiff o Vidales, pusieron su nombre en la encrucijada vanguardista; los demás, como Arciniegas, Juan Lozano, Zalamea, etc., se refugiaron en sus ficheros de reconocida pesadez intelectual, así que no podemos afirmar bajo ningún motivo que este grupo, como tal, hubiera ejercido una actividad de verdadera vanguardia; su heterogeneidad así lo indica.

\section{Piedra y Cielo}

Como dejamos anotado antes, en 1930 el gobierno conservador, cariado por la corrupción, el mal manejo y sus contradicciones internas, se viene a tierra, dando paso al Partido Liberal, que con Olaya Herrera, líder del bipartidismo hegemónico, consuma la entrega del petróleo a los consorcios extranjeros y soluciona la crisis a que estaba enfrentada la

\footnotetext{
9 Luis Vidales, Suenan timbres, op. cit., p. 20.

${ }^{10}$ Eduardo Carranza, en El Tiempo, Bogotá, 1979.
} 
burguesía nacional. La mayoría de los historiadores señala estos años como los germinales de la violencia que se desatará con todo su vigor dieciséis años después. Pero veamos lo que estaba sucediendo en el campo de la literatura.

E1 maestro Sanín Cano, siempre lúcido y oportuno, advertía a mediados de la década del 30 :

Es miseria intelectual esta a que nos condenan los que suponen que los suramericanos tenemos que vivir exclusivamente de España en materia de filosofía y letras. Las gentes nuevas del Nuevo Mundo tienen derecho a toda la vida del pensamiento ${ }^{11}$.

Pero volvimos a caer de bruces en la madre patria, y esta vez más patriotas que nunca. Un título de Juan Ramón Jiménez sirve de arrancada a la publicación de los cuadernos de poesía «Piedra y cielo», y de allí se deriva el movimiento que encabezó Eduardo Carranza, poeta este continuador de la lírica española, es decir, que retoma como fuente la tradición peninsular y sigue a los grupos de poetas que allí, hasta 1927, redescubrían a Góngora y al Siglo de Oro.

Los poetas que conformaban el grupo, fuera del ya citado Carranza, eran Jorge Rojas, Arturo Camacho Ramírez, Antonio Llanos, Tomás Vargas Osorio. Aurelio Arturo, a quien algunas veces se lo incluye entre los integrantes de este grupo, realmente no perteneció a él ni a grupo conocido. Arturo hizo de su ínsula un faro de vigía y una avanzada secreta de vanguardia.

Imposible encontrar, fuera de la influencia americanista de Neruda en Camacho Ramírez y de algunos acentos lorquianos en Rojas y Carran$\mathrm{za}$, algo que sustente el cacareado vanguardismo o revolucionarismo de este movimiento, ya que el redescubrimiento de Góngora se hubiera podido hacer sin tener que retroceder a sometimientos formales. Pero sacarle el soneto de la cabeza a los colombianos ha sido una tarea ardua y poco fructífera.

\section{«CÁNTICO»}

En 1944, y en el pleno oscurantismo que la Segunda Guerra Mundial había lanzado sobre las ideas y el pensamiento, el poeta Jaime Ibáñez inicia la publicación de una serie de cuadernos de poesía con el nombre

\footnotetext{
${ }^{11}$ Baldomero Sanín Cano, Escritos (Bogotá: Instituto Colombiano de Cultura, 1977), p. 345.
} 
de «Cántico». Y como ha sucedido regularmente en la historia de las letras colombianas en este siglo, el nombre de una revista o colección de cuadernos de poesía determina el nombre de un grupo literario, donde, por supuesto, confluyen las personalidades más heterogéneas y dispares. Se forma de esta manera el grupo de «Cántico», al que, debido a los cuadernos de poesía, también se le denominó «Cuadernícolas».

«Cántico» es una apertura con respecto a «Piedra y cielo», si bien porque cambiaron la influencia de Juan Ramón Jiménez por la de Jorge Guillén y la de Vicente Aleixandre, también porque a través de este poeta el aliento del surrealismo y de algunas corrientes de vanguardia en Europa se trasvasaron al mundo bogotano. Sin embargo, «Cántico» no representa una alborada de la vanguardia, sino más bien un punto de apoyo para la nueva generación del 50 , la que se denomina con el nombre de la revista Mito.

El poeta verdaderamente representativo y valioso del grupo «Cántico» sería Fernando Charry Lara, quien es fuerza dinámica en el entrelazamiento de mundos que originarían los pasos posteriores de la literatura colombiana, no sólo porque su obra, de implacable y ensoñadora surrealidad en sus esencias, supone un quiebre con una tradición signada por la ñoñería y el mal gusto, sino porque su presencia en el plano activo de la cultura colombiana ha desempeñado un papel dominante y esclarecedor desde entonces.

\section{EL GRUPO «MTTO»}

La creación de la revista Mito es el hecho más importante en las letras colombianas en la década del 50 . Valiente enfrentamiento contra la mordaza que los distintos gobiernos habían puesto al juego de las ideas, «Mito» salta en medio de este festín de lo horroroso abriendo las puertas al pensamiento latinoamericano y europeo. Es ésta, entonces, la primera manifestación, a nivel participativo directo, de las vanguardias en Colombia, y aunque el grupo era bastante heterogéneo y no respondía a una consigna definida, la voluntad de otorgarle al público colombiano una ventana para observar lo que desde tantos años atrás venía sucediendo en el mundo lo coloca de pleno en la vanguardia, tal vez por reflejo creativo. Pero veamos lo que dice Rafael Gutiérrez Girardot, un observador cercano de la realidad «Mito»:

La fundación de la revista Mito en 1955 significó un salto en la historia cultural de Colombia. Desde el nivel y la perspectiva de sus 
artículos, los poetas y escritores oficiales, los académicos de una novela, las "glorias locales» aparecían como lo que en realidad siempre habían sido: restos rezagados menores de su siglo XIX de campanario. Mito desenmascaró indirectamente a los figurones intelectuales de la política, al historiador de legajos canónicos y jurídicos, al ensayista «florido», a los poetas para veladas escolares, a los sociólogos predicadores de encíclicas, a los críticos lacrimosos; en suma, a la poderosa «infraestructura» cultural que satisfacía las necesidades ornamentales del retroprogresismo y que a su vez, complementariamente, tenía al país atado a concepciones de la vida y de la cultura en nada diferentes de las que dominaban entonces cualquier villorrio carpetovetónico. La revista Mito desmitificó la vida cultural colombiana y reveló, con publicaciones documentales, las deformaciones de la vida cotidiana debidas al imperio señorial. No fue una revista de "capillas" porque en ella colaboraron autores de tendencias y militancias políticas opuestas (Gerardo Molina y Eduardo Cote Lamus, por ejemplo). Su principio y su medida fueron el rigor de un trabajo intelectual, una sinceridad robesperriana, una voluntad insobornable de claridad; en suma, crítica y conciencia de la función del intelectual. Demostró que en Colombia era posible romper el cerco de la mediocridad y que, consiguientemente, ésta no es falsamente constitutiva del país ${ }^{12}$.

Es muy cierto lo que dice Gutiérrez Girardot; sin embargo, hay dos aspectos que sería válido considerar, porque ellos son explicación de por qué pudo un grupo como el de «Mito» penetrar las redes de represión que por estas fechas el gobierno ejercía. Es necesario que no se olvide que la revista era dirigida principalmente por personas como Jorge Gaitán Durán y Eduardo Cote Lamus, magníficos poetas y escritores, que estaban en contacto con lo más renovador del pensamiento mundial, pero que en el plano colombiano pertenecían a las clases altas de sus respectivas comarcas, eran jóvenes y reformistas y poetas, con aficiones por la política, pero hasta ese entonces sin una militancia activa: el uno liberal y el otro conservador; y que al fundar una revista como Mito llevan su mensaje, sin más vueltas, a los lectores de su misma clase social, ya que un pueblo estupidizado, analfabeto e ignorante como el colombiano no tenía el más mínimo acceso a tan sofisticados medios de información.

Pero cuando las ideas tienen vida no se quedan quietas en los anaqueles, y Mito cumplió con la alta misión de desacralizar la cultura colombiana, de pervertirla. Podríamos decir que Mito fue el orden estruc-

12 Rafael Gutiérrez Girardot, «La literatura colombiana, 1925-1950», Eco, agosto 1979 , núm. 214 , p. 423. 
turador de una rebelión de la conciencia que posibilitó el desorden romántico vanguardista del nadaísmo. Mito parte en dos a Colombia, deja atrás un mundo de gramáticos casposos y académicos artríticos y empieza a hablar con la voz tronante de poetas como Alvaro Mutis, Gaitán Durán, Cote Lamus; novelistas como Gabriel García Márquez y Alvaro Cepeda Samudio; ensayistas como Hernando Valencia Goelkel, Pedro Gómez Valderrama y Hernando Téllez. 
